\title{
Chemical sensor resolution requirements for near-surface measurements of turbulent fluxes
}

\author{
M. D. Rowe ${ }^{1, *}$, C. W. Fairall ${ }^{2}$, and J. A. Perlinger ${ }^{1}$ \\ ${ }^{1}$ Michigan Technological University, 1400 Townsend Dr., Houghton, MI, 49931, USA \\ ${ }^{2}$ NOAA/ESRL, 325 Broadway, Boulder, CO, 80305, USA \\ "now at: US Environmental Protection Agency, 9311 Groh Rd., Grosse Ile, MI, 48138, USA
}

Received: 7 September 2010 - Published in Atmos. Chem. Phys. Discuss.: 20 October 2010

Revised: 28 April 2011 - Accepted: 1 May 2011 - Published: 6 June 2011

\begin{abstract}
Businger and Delany (1990) presented an approach to estimate the sensor resolution required to limit the contribution of the uncertainty in the chemical concentration measurement to uncertainty in the flux measurement to $10 \%$ for eddy covariance, gradient, and relaxed eddy accumulation flux measurement methods. We describe an improvement to their approach to estimate required sensor resolution for the covariance method, and include disjunct eddy covariance. In addition, we provide data to support selection of a form for the dimensionless scalar standard deviation similarity function based on observations of the variance of water vapor fluctuations from recent field experiments. We also redefine the atmospheric parameter of Businger and Delany in a more convenient, dimensionless form. We introduce a "chemical parameter" based on transfer velocity parameterizations. Finally, we provide examples in which the approach is applied to measurement of carbon dioxide, dimethylsulfide, and hexachlorobenzene fluxes over water. The information provided here will be useful to plan field measurements of atmosphere-surface exchange fluxes of trace gases.
\end{abstract}

\section{Introduction}

In recent decades, significant developments in technologies and methods for direct measurement of turbulent atmosphere-surface exchange fluxes have been achieved. These measurements are of interest with respect to climate change, atmospheric chemistry, hydrology, ecology, and fate and transport of pollutants. Eddy covariance is usually the method of choice if a fast-response $(10 \mathrm{~Hz})$ sensor is available, for example in the case of carbon dioxide (Baldocchi, 2003; McGillis et al., 2004), water vapor (Aubinet et al.,

Correspondence to: M. D. Rowe (rowe.mark@epa.gov)
1999), and dimethylsulfide (Blomquist et al., 2010, 2006). Current methods to measure atmospheric trace gas fluxes for which fast response sensors are not available include disjunct eddy covariance (Karl et al., 2002; Rinne et al., 2008; Turnipseed et al., 2009), gradient methods, such as the modified Bowen ratio method (Perlinger et al., 2008, 2005; Walker et al., 2006), and relaxed eddy accumulation REA (Bowling et al., 1999; Businger and Oncley, 1990; Park et al., 2010); for these methods, chemical concentration measurements requiring accumulation times of up to an hour or so may be used, limited by the time of stationarity of the flux. With ongoing interest in application of these methods to additional gases, over a range of atmospheric conditions, and with new sensor technologies, it is necessary to predict the sensor resolution required to achieve a given uncertainty in the flux measurement under a given set of conditions.

Businger and Delany (1990), hereafter referred to as $\mathrm{BD} 90$, presented an analysis of sensor resolution, $R$, required to make chemical flux measurements to an estimated $10 \%$ uncertainty. Their results took the form

$R=0.1 \overline{w^{\prime} c^{\prime}} A P_{\mathrm{x}}$

where the factor 0.1 represents the $10 \%$ uncertainty requirement, $\overline{w^{\prime} c^{\prime}}$ the flux of the scalar $C$, and $A P_{\mathrm{x}}$ the "atmospheric parameter" describing the uncertainty associated with the flux method "x" (either covariance, "cov", gradient, "g", or relaxed eddy accumulation, " $r$ "). A full list of symbols with SI units is given in Appendix A. Note that $R$ has the same units as $C$. In the flux expression, $w^{\prime}$ represents turbulent variations of vertical velocity and $c^{\prime}$ turbulent fluctuation of the chemical (scalar) of interest; the overbar denotes a time average. For example, for covariance the atmospheric parameter is given as

$A P_{\mathrm{cov}}=\frac{\sigma_{\mathrm{c}}}{u_{*}\left|c_{*}\right|}=\frac{\phi_{\sigma}(z / L)}{u_{*}}$

where $\sigma_{\mathrm{c}}$ is the standard deviation of $C, u_{*}$ the friction velocity, $c_{*}=\left(-\overline{w^{\prime} c^{\prime}} / u_{*}\right)$ the chemical flux scaling parameter,

Published by Copernicus Publications on behalf of the European Geosciences Union. 
and $\phi_{\sigma}$ the similarity function for the dimensionless scalar standard deviation $\left(\sigma_{\mathrm{c}} /\left|c_{*}\right|\right)$, which is a function of sensor height, $z$, and the Monin-Obukhov stability length, $L$. For measurements over water, $z$ is measured upward from the surface. For measurements over land $z-d$ is used in place of $z$, where $d$ is the displacement height of the canopy (e.g., Kaimal and Finnigan, 1994, p. 68). For simplicity of notation, $d=0$ is used hereafter. BD90 arrived at Eq. (2) by specifying that the resolution for covariance measurements should be $10 \%$ of $\sigma_{\mathrm{c}}$.

$R=0.1 \sigma_{\mathrm{c}}=0.1 \frac{\left|\overline{w^{\prime} c^{\prime}}\right|}{u_{*}} \phi_{\sigma}(z / L)$

Similar expressions for gradient and REA methods were obtained by specifying that the resolution should be $10 \%$ of the mean gradient or $10 \%$ of the mean REA reservoir difference.

Here we offer several suggested improvements to the BD90 formulations. First, we suggest an improved approach to specify the resolution limits for the covariance method. We have also redefined $A P_{\mathrm{x}}$ by removing the factor $u_{*}$. We include a variable sampling interval, as is used in disjunct eddy covariance. Finally, we present data to support selection of a form for $\phi_{\sigma}(z / L)$ based on observations of the variance of water vapor fluctuations from recent field experiments. BD90 used temperature observations, which they pointed out are poorly defined near neutral stability, because water vapor flux and variance observations were not available.

This paper is intended to apply primarily to gaseous scalars. In principle, this basic approach can also be applied to the case of particle (aerosol) flux measurement. However, consideration of atmospheric particle transport involves the additional complexity of a size-dependent non-zero mean fall velocity and the general size dependence of the concentration and surface-removal physics. In the absence of a nearsurface source of particles, the flux to the interface is characterized by a velocity (called the deposition velocity) times the concentration. Pryor et al. (2008) offer an extensive review of particle flux observations, methods, and parameterizations of deposition velocity. For the case with a nearsurface source, complications are associated with the vertical distribution of the source and the effects of particle mean fall velocity. Further difficulty arises because most particle sensors are counters so Poisson statistics often dominate the white noise (Lenschow and Kristensen, 1985). Some theoretical development has illuminated the relationship of particles fluxes and profiles of concentration that are relevant to this discussion (Andreas et al., 2010; Fairall et al., 1990; Hoppel et al., 2002, 2005), but considerably more development is required to address resolution requirements for particle fluxes in the context of this paper. Application to particle flux measurements is deferred to a future paper, and the remainder of this paper applies to gaseous scalars.

\section{Modifications to the approach of BD90}

\subsection{Atmospheric parameter redefined}

We have redefined the atmospheric parameter by removing the factor $u_{*}$. In contrast to Eq. (1),

$R=0.1 \frac{\left|\overline{w^{\prime} c^{\prime}}\right|}{u_{*}} A P_{\mathrm{x}}^{\prime}$

In our opinion, the $u_{*}$ variable is better included with the flux term since $\overline{w^{\prime} c^{\prime}} / u_{*}$ has a weak wind speed dependence; thus, the atmospheric parameter also has a weak wind speed dependence. Defined this way, $A P_{\mathrm{x}}^{\prime}$ is unitless, in contrast to $A P_{\mathrm{x}}$, which has SI units of $\mathrm{s} \mathrm{m}^{-1}$.

\subsection{Modified eddy covariance resolution requirement}

Our revised treatment of covariance flux resolution requirements follows from the expression for the statistical sampling contribution to the error variance of the flux of $C$ computed over time interval $T$ (Blomquist et al., 2010)

$\delta F=\frac{a \sigma_{\mathrm{w}} \sigma_{\mathrm{c}}}{\sqrt{T / \tau_{\mathrm{wc}}}}$

where $a$ is a constant variously reported as 1 or 2 (Blomquist et al., 2010), $\sigma_{\mathrm{w}}$ is the standard deviation of the vertical wind velocity component, and $\tau_{\mathrm{wc}}$ is the integral time scale of the $w c$ covariance time series. We then represent the scalar variance as the sum of the true atmospheric variance (turbulent fluctuations) and a contribution from sensor white noise, each with its own integral time scale.

$\delta F^{2}=\frac{a^{2} \sigma_{\mathrm{w}}^{2} \sigma_{\mathrm{c}_{\mathrm{a}}}^{2}}{T / \tau_{\mathrm{wc}}}+\frac{a^{2} \sigma_{\mathrm{w}}^{2} \sigma_{\mathrm{c}_{\mathrm{n}}}^{2}}{T / \tau_{\mathrm{c}_{\mathrm{n}}}}$

Here we have considered only two possible sources of variance for $C$; we assume the sources are independent so the variances sum. For surface layer turbulence processes, the turbulent flux drives variance in the variables, which can be computed from Monin-Obukhov similarity theory

$\sigma_{\mathrm{c}_{\mathrm{a}}}=\left|\overline{\frac{w^{\prime} c^{\prime}}{u_{*}}}\right| \phi_{\sigma}(z / L)$

Because we are estimating the covariance flux with highspeed measurements that resolve most of the frequency components that contribute to the flux, the relevant time scale for the turbulence process is the integral time scale associated with the turbulent fluctuations. In the surface layer, this time scale can be estimated from the frequency, $f_{\mathrm{m}}$, corresponding to the peak in the vertical velocity or scalar variance spectral density or, alternatively, the $w-c$ cospectrum

$\tau_{\mathrm{wc}}=1 /\left(2 \pi f_{\mathrm{m}}\right)$

White noise is not autocorrelated, but the highest frequencies are eliminated by digitizing the signal at the sampling 
interval. For this case of band-limited white noise, we can compute the integral time scale of the white noise. The noise could be simply electronic noise or Poisson counting statistics from a photon detector. Band-limited white noise is characterized by a constant variance-spectral value from 0 to a maximum frequency (Nyquist frequency), $f_{\mathrm{x}}$ :

$\phi_{\mathrm{c}_{\mathrm{n}}}(f)=\phi_{\mathrm{c}_{\mathrm{n}}}=\sigma_{\mathrm{c}_{\mathrm{n}}}^{2} / f_{\mathrm{x}} \quad f<f_{\mathrm{x}}$

$\phi_{\mathrm{c}_{\mathrm{n}}}(f)=0 \quad f>f_{\mathrm{x}}$

The integral time scale for band-limited white noise is (Blomquist et al., 2010)

$\tau_{\mathrm{c}_{\mathrm{n}}}=\frac{1}{4 f_{\mathrm{x}}}$

Substituting this expression into Eq. (6)

$\delta F=\frac{a \sigma_{\mathrm{w}}}{\sqrt{T}}\left[\sigma_{\mathrm{c}_{\mathrm{a}}}^{2} \tau_{\mathrm{wc}}+\sigma_{\mathrm{c}_{\mathrm{n}}}^{2} /\left(4 f_{\mathrm{x}}\right)\right]^{1 / 2}$

We now specify the $10 \%$ condition as follows: the white noise of the sensor cannot account for more than $10 \%$ of the total uncertainty in $F$. We specify this by requiring that adding a small white noise term will increase the uncertainty by $10 \%$. The uncertainty without noise is obtained from Eq. (11) by neglecting the $\sigma_{\mathrm{c}_{\mathrm{n}}}^{2}$ term; thus the ratio of the uncertainty with noise to the uncertainty without noise is

$\frac{\left[\sigma_{\mathrm{c}_{\mathrm{a}}}^{2} \tau_{\mathrm{wc}}+\sigma_{\mathrm{c}_{\mathrm{n}}}^{2} /\left(4 f_{\mathrm{x}}\right)\right]^{1 / 2}}{\left[\sigma_{\mathrm{c}_{\mathrm{a}}}^{2} \tau_{\mathrm{wc}}\right]^{1 / 2}}=1.1$

$=\left[1+\sigma_{\mathrm{c}_{\mathrm{n}}}^{2} /\left(4 f_{\mathrm{x}} \sigma_{\mathrm{c}_{\mathrm{a}}}^{2} \tau_{\mathrm{wc}}\right)\right]^{1 / 2} \approx 1+\frac{1}{2} \sigma_{\mathrm{c}_{\mathrm{n}}}^{2} /\left(4 f_{\mathrm{x}} \sigma_{\mathrm{c}_{\mathrm{a}}}^{2} \tau_{\mathrm{wc}}\right)$

If we equate $R$ with $\sigma_{\mathrm{c}_{\mathrm{n}}}$ then this condition applied to Eq. (12) is

$\sigma_{\mathrm{c}_{\mathrm{a}}}^{2} \tau_{\mathrm{wc}}=10 R^{2} /\left(8 f_{\mathrm{x}}\right)$

or

$R=0.1 \sigma_{\mathrm{c}_{\mathrm{a}}} \sqrt{80 \tau_{\mathrm{wc}} f_{\mathrm{x}}}=0.1\left|\frac{\overline{w^{\prime} c^{\prime}}}{u_{*}}\right| \phi_{\sigma}(z / L) \sqrt{80 \tau_{\mathrm{wc}} f_{\mathrm{x}}}$

Note that Eq. (14) is similar to Eq. (3) except for the additional factor of $\sqrt{80 \tau_{\mathrm{wc}} f_{\mathrm{x}}}$. For example, if the signals are digitized at 10 times per second (Nyquist frequency $f_{\mathrm{x}}=$ $5 \mathrm{~Hz}$ ), this factor is on the order of 40 for measurements at a height of $20 \mathrm{~m}$. This criterion implies direct covariance measurements require about 40 times less resolution for fast sensors used in flux estimates than that suggested by BD90. BD90 assumed a worst case scenario in which the noise is well correlated with $c^{\prime}$, whereas we assume white noise that is not correlated to $c^{\prime}$. Note that Eq. (14) is also related to the "figure of merit" for covariance measurements defined by Lenschow and Kristensen (1985) for sensors that obtain concentration through counting statistics (e.g., a photon detector or aerosol size spectrometer). In their Eq. (28), they take the ratio of error variance contributed by uncorrelated noise to that contributed by atmospheric variability.

\subsection{Disjunct eddy covariance resolution requirement}

In disjunct eddy covariance (DEC), a fast $(\sim 0.1 \mathrm{~s})$ air sample is collected at a longer interval $(\sim 1$ to $30+\mathrm{s})$ so that a relatively slow sensor may be used to measure the scalar concentration. The statistical sampling error variance of the flux measurement is greater for DEC than for conventional EC because fewer samples are collected over the averaging period (Lenschow et al., 1994). In addition, the contribution of the scalar sensor "white noise" is relatively greater for DEC than for EC. In EC, the noise contribution is reduced because the sampling interval is much less than the covariance integral time scale, Eq. (14); several scalar measurements are averaged in the time it takes a typically-sized eddy to pass the sensor, providing some reduction in sensor noise by averaging.

For DEC, Lenschow et al. (1994, Eq. 58) gave the statistical sampling contribution to the normalized flux error variance as,

$\frac{\delta F^{2}}{\sigma_{\mathrm{wc}}^{2}} \frac{T}{\tau_{\mathrm{wc}}}=\frac{\Delta}{\tau_{\mathrm{wc}}} \operatorname{coth}\left(\frac{\Delta}{2 \tau_{\mathrm{wc}}}\right)$

where $\Delta$ is the disjunct sampling interval. The term on the right hand side limits to 2 for $\Delta \ll \tau_{\mathrm{wc}}$, which is equivalent to Eq. (5) for EC (with $a=\sqrt{2}$ ), and to $\Delta / \tau_{\mathrm{wc}}$ for $\Delta \gg \tau_{\mathrm{wc}}$, which is equivalent to Eq. (4) of Rinne et al. (2008). In practice, $\Delta$ may be about $1 \mathrm{~s}$ in the case of virtual DEC (Karl et al., 2002) or 2 to $40 \mathrm{~s}$ in DEC (Rinne et al., 2008; Turnipseed et al., 2009), which is on the order of $\tau_{\mathrm{wc}}$. It is desirable to keep $\Delta$ as close as possible to conventional EC sampling interval of $0.1 \mathrm{~s}$, so we keep Eq. (15) rather than using one of the limits. Equation (15) can be rearranged, with the substitution $\sigma_{\mathrm{wc}} \approx a \sigma_{\mathrm{w}} \sigma_{\mathrm{c}}$, and substituted for Eq. (5) in the derivation of Eq. (6) to obtain a general expression for the statistical sampling error variance of disjunct or conventional EC with the sensor white noise contribution as a separate term,

$\delta F^{2}=\frac{a^{2} \sigma_{\mathrm{w}}^{2} \sigma_{\mathrm{c}_{\mathrm{a}}}^{2}}{T / \Delta} \operatorname{coth}\left(\frac{\Delta}{2 \tau_{\mathrm{wc}}}\right)+\frac{a^{2} \sigma_{\mathrm{w}}^{2} \sigma_{\mathrm{c}_{\mathrm{n}}}^{2}}{T / \tau_{\mathrm{c}_{\mathrm{n}}}} \operatorname{coth}\left(\frac{\Delta}{2 \tau_{\mathrm{wc}}}\right)$

Applying Eq. (10) to DEC,

$\tau_{\mathrm{c}_{\mathrm{n}}}=\frac{\Delta}{2}$

And following the derivation of Eq. (14) with Eq. (16) in place of Eq. (6), we have,

$R=0.1 \sigma_{\mathrm{c}_{\mathrm{a}}} \sqrt{40}$

Equation (18) can be obtained directly from Eq. (14) by substituting $\tau_{\mathrm{wc}}=\Delta$ and $f_{\mathrm{x}}=\frac{1}{2 \Delta}$. Equation (14) can be applied on a continuous scale from EC to long interval DEC: for $\Delta>\tau_{\mathrm{wc}}, \Delta$ is substituted for $\tau_{\mathrm{wc}}$ in Eq. (14) as the relevant time scale. In all cases, $f_{\mathrm{x}}=\frac{1}{2 \Delta}$. As the sample interval is increased from $0.1 \mathrm{~s}$, typical of EC, to values exceeding $\tau_{\mathrm{wc}}$, covering the range of DEC, a greater requirement is placed 


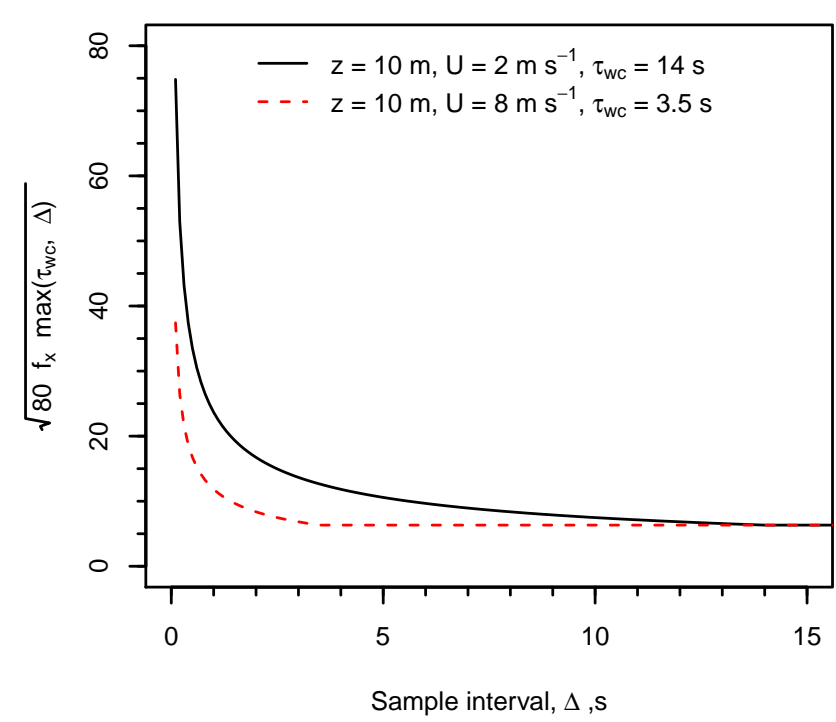

Fig. 1. As the sample interval is increased from $0.1 \mathrm{~s}$, typical of conventional eddy covariance, to values exceeding the covariance integral time scale, $\tau_{\mathrm{wc}}$, covering the range of disjunct eddy covariance, a greater requirement is placed on sensor precision, as indicated by the decreasing value of the radical term in Eq. (14).

on sensor precision, as indicated by the decreasing value of the radical term in Eq. (14) (Fig. 1).

Equation (18) is a somewhat trivial outcome that stems from our definition of the required sensor resolution in Eqs. (12-14). Sometimes there is a tradeoff between $\Delta$ and $\sigma_{\mathfrak{c}_{\mathrm{n}}}$ (e.g., Turnipseed et al. 2009); greater sampling time (greater mass collected) improves measurement precision. In that case, Eq. (16) may be used to consider the tradeoff between sensor resolution and statistical sampling uncertainty, while attempting to minimize the overall flux uncertainty.

\section{Atmospheric stability dependence of $\sigma$ and $\tau$}

In order to apply Eq. (14), it is necessary to estimate the scalar standard deviation and integral time scale. In this section, we present data to support selection of a form of the stability-dependent scalar standard deviation similarity function, and then substitute the similarity relationships into Eq. (14) to yield a form that is useful in field experiments.

\subsection{Updated similarity function for the standard deviation of a scalar}

In surface layer scaling theory, the dimensionless standard deviation of a scalar due to turbulent fluctuations is defined through Eq. (7), where

$\sigma_{\mathrm{c}} / c_{*}=\phi_{\sigma}(z / L)=A f_{\mathrm{c}}(z / L)$
Here $A$ is a dimensionless constant with a value set so that $f_{\mathrm{c}}(0)=1.0$. Panofsky and Dutton (1984) present mixing arguments (p. 170-171) that

$f_{\mathrm{c}}(z / L)=\phi_{\mathrm{c}}(z / L)$

where

$\phi_{\mathrm{c}}(z / L)=\frac{\kappa z}{c_{*}} \frac{\partial \bar{C}}{\partial z}$

is the stability function for the dimensionless mean gradient of a scalar. Here $\kappa=0.4$ is the von Kármán constant.

Another approach to parameterize the scalar variance is to use the variance budget equation; neglecting the turbulent transport term, the net production of variance is a balance of gradient generation and dissipation (Edson and Fairall, 1998)

$\frac{D\left(\overline{c^{\prime 2}}\right)}{D t}=-2 \overline{w^{\prime} c^{\prime}} \frac{\partial \bar{C}}{\partial z}-N_{c}=0$

where $N_{\mathrm{c}}$ is the rate of dissipation of the variance of $C$ via turbulent mixing and molecular viscosity. We can represent $N_{\mathrm{c}}$ through the turbulent mixing/dissipation time scale

$N_{\mathrm{c}}=\overline{c^{\prime 2}} / \tau_{\mathrm{cD}}=\sigma_{\mathrm{c}}^{2} / \tau_{\mathrm{cD}}$

Using Eqs. (21-23) and the definition of $c_{*}$, we find

$\frac{\sigma_{\mathrm{c}}^{2}}{c_{*}^{2}}=\frac{2 u_{*}}{\kappa z} \tau_{\mathrm{cD}} \phi_{\mathrm{c}}$

We use the standard deviation of the vertical velocity, $\sigma_{\mathrm{w}}$, and its corresponding similarity function, $f_{\mathrm{w}}$ (Kaimal and Finnigan, 1994, p. 16), to define the mixing time scale

$\sigma_{\mathrm{w}}=1.25 u_{*} f_{\mathrm{w}}(z / L)$

$f_{\mathrm{W}}(z / L)=[1+3|z / L|]^{1 / 3} \quad z / L<0$

$f_{\mathrm{W}}(z / L)=1+0.2(z / L) \quad z / L>0$

$\tau_{\mathrm{cD}} \cong \frac{\kappa z}{\sigma_{\mathrm{w}}}=\frac{\kappa z}{1.25 u_{*} f_{\mathrm{w}}(z / L)}$

Substituting Eqs. (25a-d) into Eq. (24) and combining constants into one empirical parameter yields

$\frac{\sigma_{\mathrm{c}}}{c_{*}}=A\left[\frac{\phi_{\mathrm{c}}(z / L)}{f_{\mathrm{w}}(z / L)}\right]^{1 / 2}$

Observations of temperature variance from the Kansas experiment (Kaimal and Finnigan, 1994) indicate that Eq. (20) is reasonable for unstable conditions $(z / L)<0$, but the stability dependence of $f_{\mathrm{c}}$ for stable conditions $(z / L)<0$ is much weaker than that of $\phi_{\mathrm{c}}$. Observations of temperature and humidity variance over land consistently show that in unstable conditions, $\phi_{\sigma}$ is well represented by

$\phi_{\sigma}=A(1-B z / L)^{-1 / 3} \quad z / L<0$ 
with values of $A$ of 3 to 4 and $B 20$ to 35 . For example, Andreas et al. (1998) found $A=3.2$ and 4.1 for temperature and humidity, respectively, with $B=28.4$; Choi et al. (2004) give $A=3.7$ and 3.5 for temperature and humidity, respectively, with $B=34.5$ and 32.7; Blomquist et al. (2010) suggest $A=3.0$ and $B=20$.

Observations for stable conditions are more problematic because the turbulent fluxes are small and a near-constant flux surface layer may be shallow. Over the ocean stable conditions are associated with fog and water condensation that interferes with sensors (especially optical fast humidity sensors). For temperature there is also infrared radiative heat transfer in strong vertical temperature gradients that may upset the scaling relationships. The Surface Heat Budget of the Arctic (SHEBA) field program offers a one-year set of observations of fluxes from 5 levels of sonic anemometers (Grachev et al., 2003). These data indicate $\phi_{\sigma}$ for potential temperature increases weakly with $z / L$. However, when $z / L$ exceeds about 2 the five levels no longer collapse to a single value - indicating that similarity scaling is breaking down. Andreas et al. (1998) also found weak stability dependence for $0<z / L<1$.

Published observations of dimensionless scalar variance over the ocean are sufficiently rare that we include results for humidity variance from two ship-based field programs: the New England Air Quality Experiment (NEAQS) and the Stratus07 field program. NEAQS was conducted on the NOAA R/V Ronald H. Brown in the Gulf of Maine in the summer of 2004. Details of the observations are reported by Fairall et al. (2006). The Stratus07 project was also conducted on the Brown off the coast of Chile in 2007 (see DeSzoeke et al., 2009). Velocity and temperature turbulence were measured with sonic anemometers and fast humidity fluctuations were measured with near-infrared absorption hygrometers - hardware, ship motion correction, and processing details are reported by Fairall et al. (2006).

Observations of dimensionless scalar variance are plotted in Fig. 2, and compared to several mathematical representations. Individual hourly observations from Stratus07 show an excellent fit with land-derived unstable stability functions (Fig. 2, left panel). The Stratus07 field program had large sea-air humidity contrast (about $5 \mathrm{~g} \mathrm{~kg}^{-1}$ ), the latent heat flux was substantial (ca. $85 \mathrm{~W} \mathrm{~m}^{-2}$ ), and there was essentially no precipitation so it was ideal to measure the humidity variance and the scaling parameters (unstable conditions dominated). We chose the NEAQS field program because stable conditions dominated. However, fog, precipitation and internal boundary layers associated with offshore flow were common. Sea-air humidity contrast was modest (about $2.5 \mathrm{~g} \mathrm{~kg}^{-1}$ ) and so were the latent heat fluxes (about $25 \mathrm{~W} \mathrm{~m}^{-2}$ ). Individual hourly observations from NEAQS had about ten times the scatter of those from Stratus07, so we averaged the data in bins of $z / L$. Bulk $z / L$ values (computed with COARE 3.0) were used to avoid artificial correlation. The results for the stable NEAQS averages are shown in Fig. 2, right hand panel.
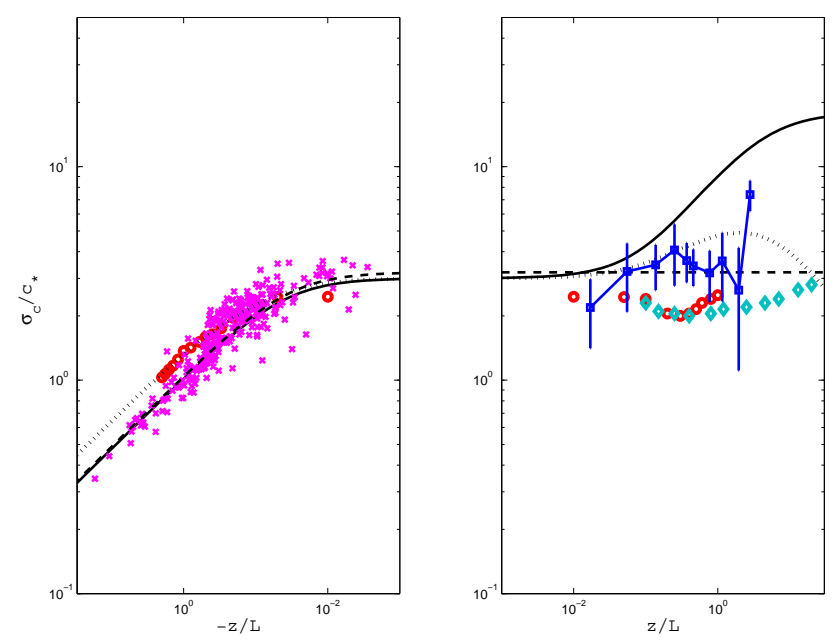

Fig. 2. Dimensionless scalar standard deviation versus stability, $z / L$ : left panel, unstable conditions $(z / L<0)$ and right panel, stable conditions $(z / L>0)$. Lines are mathematical representations: solid Blomquist et al. (2010, 26a, b); dashed - Andreas et al. (1998, Eq. 5.9a, b, $C=3.2$ ), and dotted - Eq. (21) with the COARE3.0 gradient function and Eq. (20). The magenta x's are hourly data from Stratus07; solid circles - digitized from BD90 Fig. 1; Diamonds data from SHEBA; and squares - data from NEAQS.

Also shown in the figure are points digitized from the line in BD90 Fig. 2, three of the mathematical representations discussed above, and the stable SHEBA results for temperature variance. The unstable observations are consistent and imply a neutral value for $\phi_{\sigma}$ between 3.0 and 4.0. Humidity observations on the stable side imply a constant value or a weak increase with increasing stability. For subsequent calculations, we selected the functions of Andreas et al. (1998, $5.9 \mathrm{a}, \mathrm{b})$ as the closest approximation to the data.

\subsection{Incorporation of similarity functions into the resolution expression for covariance}

We can add detail to Eq. (14) using stability functions for $\sigma_{\mathrm{c}_{\mathrm{a}}}$ from Andreas et al. (1998) and for $\tau_{\mathrm{wc}}$ from Blomquist et al. (2010). Each of the key variables is expressed in terms of scaling variables and a dimensionless stability dependence, $f(z / L)$, scaled to have a value of 1.0 at $(z / L)=0$ :

$$
\begin{aligned}
\sigma_{\mathrm{c}_{\mathrm{a}}} & =\left|\frac{\overline{w^{\prime} c^{\prime}}}{u_{*}}\right| \phi_{\sigma}(z / L)=\left|\overline{\frac{w^{\prime} c^{\prime}}{u_{*}}}\right| A f_{\mathrm{c}}(z / L) \\
\tau_{\mathrm{wc}} & =b \frac{z}{U_{\mathrm{r}}} f_{\tau}(z / L)
\end{aligned}
$$

where $A=3.2$ (Andreas et al., 1998). The coefficient $b$ is fairly uncertain but is near 3. Here we use $b=2.8$ (Blomquist et al., 2010). $U_{\mathrm{r}}$ is the mean wind speed relative to the sensor (not corrected for platform motion). The stability functions are

$f_{\tau}(z / L)=[\min (5, \max (0.5,1+0.6 z / L))]^{-1}$ 


$$
\begin{array}{ll}
f_{\mathrm{c}}(z / L)=[1+28.4|z / L|]^{-1 / 3} & z / L<0 \\
f_{\mathrm{c}}(z / L)=1 & z / L>0
\end{array}
$$

where Eq. (29b and c) are equivalent to Andreas et al. (1998, Eq. 5.9a, b). We substitute Eq. (29) into Eq. (14) to obtain the expression for sensor resolution required to limit at $10 \%$ the contribution of sensor noise to uncertainty in flux measured by eddy covariance. To make the expression general for EC or DEC, we further substitute $f_{\mathrm{x}}=\frac{1}{2 \Delta}$, and use the greater of $\tau_{\mathrm{wc}}$ or $\Delta$ (see Sect. 2.3).

$$
R=0.1\left|\frac{\overline{w^{\prime} c^{\prime}}}{u_{*}}\right| A f_{\mathrm{c}}(z / L) \sqrt{\frac{40}{\Delta} \max \left(b \frac{z}{U_{\mathrm{r}}} f_{\tau}(z / L), \Delta\right)}
$$

\subsection{Uncertainty in empirical expressions for turbulence statistics}

Empirical expressions for turbulence statistics have associated uncertainty. As an example indicating the combined effect of uncertainty in several parameters, Blomquist et al. (2010) compared relative error computed from the expression given as Eq. (11) in our manuscript to relative standard deviation of dimethylsulfide fluxes measured during the Southern Ocean GASEX project. Estimates of $\sigma_{\mathrm{w}}, \sigma_{\mathrm{c}_{\mathrm{a}}}$, and $\tau_{\mathrm{wc}}$ are required to evaluate Eq. (11). Figure 9 of Blomquist et al. (2010) shows that Eq. (11) is biased by about 0 to $-30 \%$ over the range of wind speed for that data set. Based on Fig. 2 and associated discussion, uncertainty in $\sigma_{\mathrm{c}_{\mathrm{a}}}$ from Eqs. (28a), (29b-c) is about $10 \%$ (unstable) and $30 \%$ (stable). Uncertainty in $\tau_{\mathrm{wc}}$ from Eqs. (28b) and (29a) is about $100 \%$ (unstable) and $50 \%$ (stable), based on one co-author's own data (CWF) and Lee et al. (2004). Uncertainty in $\psi(z / L)$ is about $10 \%$ (Fairall et al., 2003). $\psi$ is the stability function for the dimensionless vertical profile of a scalar (from Fairall et al., 2003).

\section{Results and discussion}

\subsection{Comparison of required sensor resolution for three flux measurement methods using the redefined atmospheric parameter}

For the modified atmospheric parameters described by Eq. (4) we have

$$
\begin{aligned}
A P_{\mathrm{cov}}^{\prime}= & A f_{\mathrm{c}}(z / L) \sqrt{\frac{40}{\Delta} \max \left(b \frac{z}{U_{\mathrm{r}}} f_{\tau}(z / L), \Delta\right)} \\
A P_{\mathrm{g}}^{\prime}= & (\sqrt{2} \kappa)^{-1}\left[\ln \left(z_{2} / z_{1}\right)-\psi_{\mathrm{c}}\left(z_{2} / L\right)+\psi_{\mathrm{c}}\left(z_{1} / L\right)\right] \\
& =(\sqrt{2} \kappa)^{-1} G \\
A P_{\mathrm{r}}^{\prime}= & \frac{u_{*}}{\sqrt{2} b_{\mathrm{th}} \sigma_{\mathrm{w}}}=\frac{1}{1.8 b_{\mathrm{th}} f_{\mathrm{w}}(z / L)}
\end{aligned}
$$

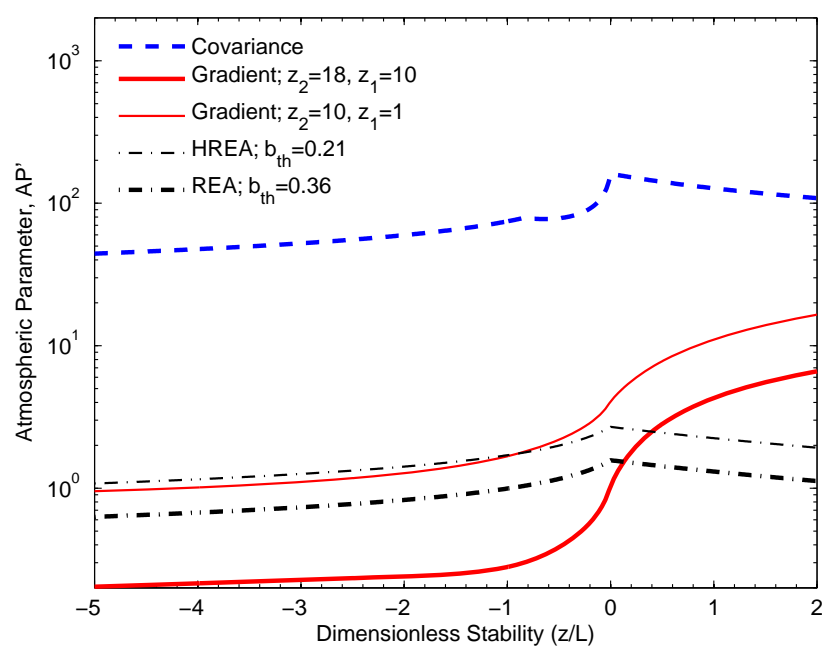

Fig. 3. Comparison of the required sensor resolution as a function of stability for three flux measurement methods as indicated by the redefined atmospheric parameter, $A P_{\mathrm{x}}^{\prime}$. Wind speed is $8 \mathrm{~m} \mathrm{~s}^{-1}$ and instrument height is $18 \mathrm{~m}$ for covariance and $(\mathrm{H}) \mathrm{REA}$ methods. Two cases are shown for the gradient method: for the gradient method, a typical ocean, ship-based installation with $z_{2}=18 \mathrm{~m}$ and $z_{1}=10 \mathrm{~m}$, and a lake or land-based installation with $z_{2}=10 \mathrm{~m}$ and $z_{1}=1 \mathrm{~m}$, are considered.

Equation (31b and c) follow from the derivation of BD90 except that a factor of $\sqrt{2}$ is applied to the uncertainty in concentration measurement to account for the fact that BD90 set $R$ equal to $\delta\left(\Delta C_{21}\right)$, while here $R$ is set equal to $\delta(C)$. Here $z_{2}$ and $z_{1}$ are the two heights for the gradient measurement, $\psi$, and $b_{\text {th }}$ the three-reservoir REA calibration coefficient (a function of the threshold used for the up/down reservoirs). In Eq. (31b), $G$ is introduced as shorthand notation for the stability term in square brackets.

Figure 3 shows examples of $\mathrm{AP}_{\mathrm{x}}^{\prime}$ values for a typical ship-based application. Here we have used $U_{\mathrm{r}}=8 \mathrm{~m} \mathrm{~s}^{-1}$, $z=18 \mathrm{~m}$. For the gradient method, a typical ocean, shipbased installation with $z_{2}=18 \mathrm{~m}$ and $z_{1}=10 \mathrm{~m}$, and a lake or land-based installation with $z_{2}=10 \mathrm{~m}$ and $z_{1}=1 \mathrm{~m}$, are considered. For REA, two values of $b_{\text {th }}$ were considered: $b_{\mathrm{th}}=0.36$ for the method of Businger and Oncley (1990) with a threshold of $0.6 \sigma_{\mathrm{w}}$, and $b_{\mathrm{th}}=0.21$ for the asymmetrical hyperbolic REA method of Bowling et al. (1999) with a hole size of 1.10 (see their Table 1). Of the three flux measurement methods, eddy covariance has the least stringent requirement for sensor resolution over the full range of stability. However, if a fast-response sensor is not available for the chemical of interest, it is necessary to consider other methods. Among gradient and REA, gradient is a favorable choice for stable conditions, while REA may have a less stringent resolution requirement under unstable conditions, depending on selection of the threshold for REA, or hole size for HREA, that determines the value of $b_{\mathrm{th}}$. 


\subsection{Predicted sensor resolution requirements for turbulent flux measurements of specific chemicals}

In order to use Eq. (4) to estimate the sensor resolution that will be required in a planned field experiment, it is necessary to estimate the magnitude of the flux that will be measured. To this end, we substitute transfer velocity, $k$, parameterizations into Eq. (4) for air-water exchange and for deposition fluxes to specific land cover types.

In the case of air-water gas exchange, the flux is commonly parameterized as

$\overline{w^{\prime} c^{\prime}}=\alpha_{\mathrm{c}} k_{\mathrm{c}} \Delta C$

where $\alpha_{\mathrm{c}}$ is the dimensionless aqueous solubility of $C$, and $\Delta C=C_{\mathrm{w}} / \alpha_{\mathrm{c}}-C_{\mathrm{a}}$ is the difference between the gaseous concentration of $C$ at specified height above the water and that in equilibrium with the aqueous phase in the air diffusive layer (Blomquist et al., 2006; Fairall et al., 2000).

In the case of gaseous deposition to specific land cover types, the transfer velocity is often parameterized as several transfer resistances in series and in parallel, in analogy to an electrical circuit (Wesely, 1989; Zhang et al., 2003, 2002). The condensed phase concentration is not as easily defined as in the case of air-water exchange because several compartments are involved (leaves, soil, etc.), and the chemical concentrations in these compartments are often not known. For reactive chemicals or those that are very soluble in the condensed phase(s), it may be reasonable to neglect emission. One-way exchange (deposition) is parameterized as,

$\overline{w^{\prime} c^{\prime}}=-k_{\mathrm{c}} C_{\mathrm{a}}$

where the transfer velocity is a function of chemical properties, land surface properties, and meteorological variables (Zhang et al., 2003).

Alternative parameterizations are available for chemicals that undergo two-way exchange. For example, detailed mechanistic models exist to scale exchange from leaf to canopy considering physiological and energy balance processes for biogenic chemicals such as carbon dioxide and water vapor (Baldocchi and Harley, 1995), nitrogen (Leuning et al., 1995), and terpenes (Baldocchi et al., 1999; Wolfe and Thornton, 2011). In addition, apolar, persistent organic pollutants and elemental mercury may be modeled as passively partitioning between air and foliage (Lindberg et al., 1992; Mackay et al., 2006).

Equations (32) or (33) can be substituted for the flux in Eq. (4) to estimate the required sensor resolution. We then normalize $R$ by $\Delta C$, for air-water exchange, or by $C_{\mathrm{a}}$ for deposition to land surface, to introduce a "chemical parameter", $C P_{\text {c }}$, that has minimal dependence on atmospheric variables. For air-water exchange,

$$
\frac{R}{|\Delta C|}=0.1 C P_{\mathrm{c}} A P_{\mathrm{x}}^{\prime}
$$

$$
C P_{\mathrm{c}}=\alpha_{\mathrm{c}} \frac{k_{\mathrm{c}}}{u_{*}}
$$

or, for deposition to land surface,

$$
\begin{aligned}
& \frac{R}{C_{\mathrm{a}}}=0.1 C P_{\mathrm{c}} A P_{\mathrm{x}}^{\prime} \\
& C P_{\mathrm{c}}=\frac{k_{\mathrm{c}}}{u_{*}}
\end{aligned}
$$

Values of $C P_{\mathrm{c}}$ for air-water exchange of chemicals having a range in solubility were calculated using COARE 3.0 for neutral stability, $U_{0}=11 \mathrm{~m} \mathrm{~s}^{-1}, u_{*}=0.4 \mathrm{~m} \mathrm{~s}^{-1}, 10$-m reference height for $C_{\mathrm{a}}$, and are plotted in Fig. 4. Acid-base reactions and other chemical transformations were neglected. This figure represents a scenario in which we examine the effect of variable $\alpha_{\mathrm{c}}$ on ability to measure flux with $\Delta C$ fixed. It is possible to fix $\Delta C$ and vary $\alpha_{\mathrm{c}}$ even though $\alpha_{\mathrm{c}}$ is used to calcultate $\Delta C$ because $C_{\mathrm{a}}$ and $C_{\mathrm{w}}$ can vary independently. The programs of Johnson (2010) were used to estimate $S c$ and temperature-dependent solubility at $20^{\circ} \mathrm{C}$ for fresh water using data compiled by Sander (1999). Solubility values for additional compounds were obtained elsewhere: $\mathrm{Hg}(0)$ (Sanemasa, 1975), $\mathrm{HgCl}_{2}$ and $\mathrm{Hg}(\mathrm{OH})_{2}$ (Lindqvist, 1985), and 8-2 fluorotelomer alcohol (Hilal et al., 2004, SPARC On-Line Calculator http://archemcalc.com/sparc/). $C P_{\mathrm{c}}$ varies over four orders of magnitude for the range of chemicals considered, mainly as a function of aqueous solubility. Schmidt numbers vary over a much more limited range than solubility (Fig. 4). Chemicals that partition more strongly into the aqueous phase (i.e., greater values of $\alpha_{\mathrm{c}}$ ) have greater values of $C P_{\mathrm{c}}$, and thus a less restrictive sensor resolution is required for a given value of $A P_{\mathrm{x}}^{\prime}$. Note that $C P_{\mathrm{c}}$ levels off at high $\alpha_{\mathrm{c}}$ where the transfer becomes limited by the atmospheric resistance.

Values of maximum $C P_{\mathrm{c}}$ are plotted for deposition of gases to forests, crops, and water surface in Fig. 5 using deposition velocities at 20-m reference height given by Zhang et al. (2003, Table 2). The deposition velocities represent maximum values predicted by the model of Zhang et al. for reasonable combinations of meteorological variables for each land cover type, and we used the maximum value of $u_{*}$ given by Zhang et al. for each land cover type to calculate $C P_{\mathrm{c}-\max }$. For deposition to water, greater values of $C P_{\mathrm{c}-\max }$ are associated with greater partitioning into the aqueous phase (i.e., greater values of $\alpha$ ) as in Fig. 4, and also with greater reactivity (greater values of $\beta$ ). As in airwater exchange, the greatest values of $C P_{\mathrm{c}-\max }$ (right-hand side of Fig. 5) are limited by the atmospheric and boundary layer resistance. Relatively water-soluble and/or reactive compounds in Fig. 5 have similar values of $C P_{\mathrm{c}-\max }$ to relatively water-soluble compounds in Fig. 4 (right-hand side of both figures). Zhang et al. reported maximum deposition velocities of zero for values less than $0.04 \mathrm{~m} \mathrm{~s}^{-1}$, which, of the land-use categories included in Fig. 5, occurred only for deposition to water surface for less water-soluble/reactive 


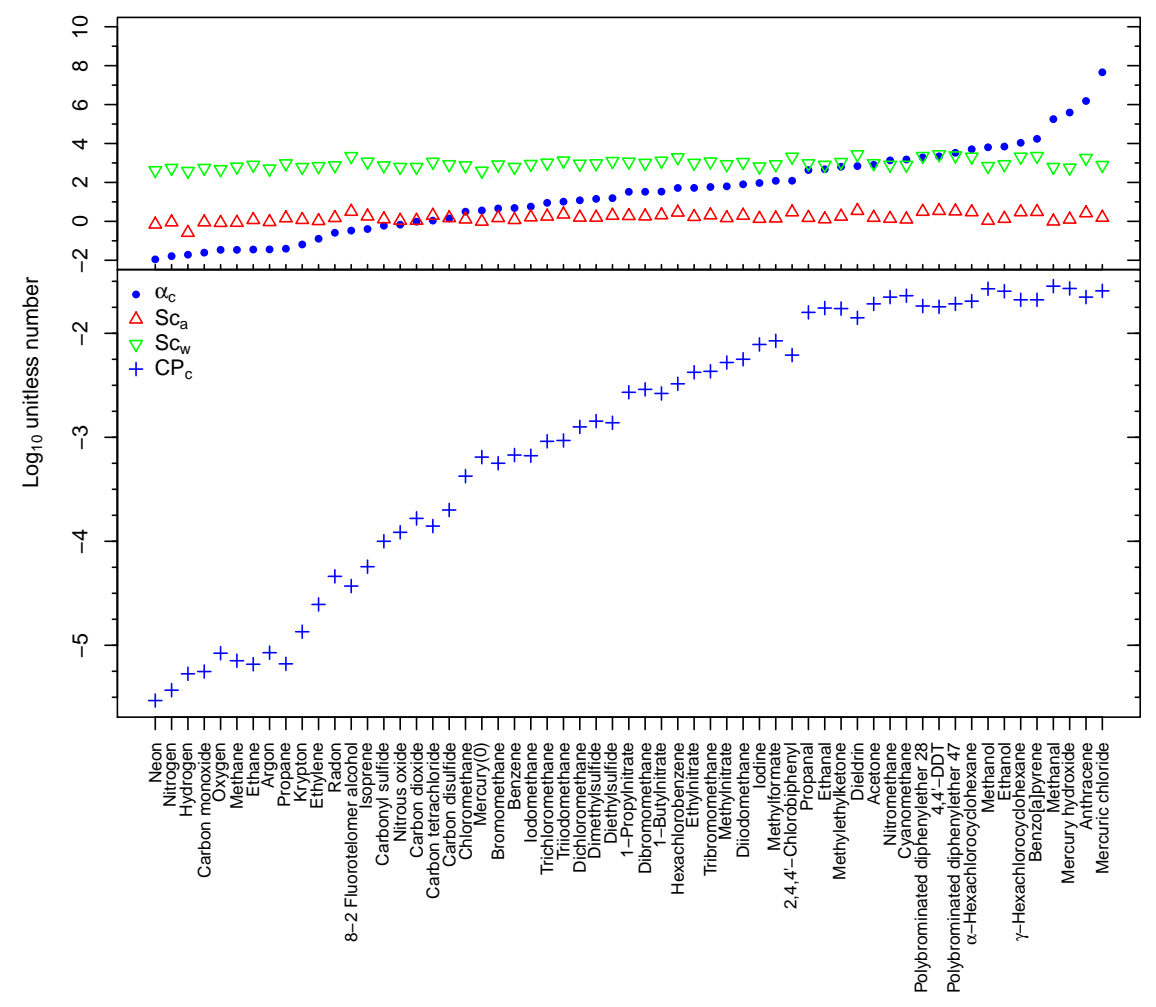

Fig. 4. The chemical parameter, $C P_{\mathrm{c}}$, computed as in Eq. (34), for chemicals having a range in aqueous solubility at $20^{\circ} \mathrm{C}$. Additional assumptions are stated in the text. $C P_{\mathrm{c}}$ can be multiplied by $A P_{\mathrm{x}}^{\prime}$ (Fig. 3) to obtain the required sensor resolution for a given flux measurement method. Dimensionless solubility and Schmidt numbers in air and water are shown for comparison.

compounds (left-hand side of Fig. 5); these values were omitted from Fig. 5. The model of Zhang et al. predicts slightly greater $C P_{\mathrm{c}-\max }$ values for deposition to land surfaces relative to water surface for water-soluble/reactive compounds, and much greater values for less water-soluble/reactive compounds, which suggests that sensor resolution requirements are less stringent for land-based measurements than over water. However, it should be noted that the model of Zhang et al. does not account for volatilization, which may be significant relative to deposition for specific chemicals and land-use categories. Transfer velocity models have not been validated for a wide variety of chemical species. Additional flux measurements are needed to validate and improve transfer velocity models.

\subsection{Example applications}

The required sensor resolution for a given chemical, flux measurement method, land surface type, and atmospheric stability can be estimated by obtaining $A P_{\mathrm{x}}^{\prime}$ from Eq. (31) or Fig. 3, $C P_{\mathrm{c}}$ from a transfer velocity parameterization (e.g., Figs. 4-5), and use of Eq. (34) or (35). Electronic supplemental material is associated with the online version of this manuscript that gives the data plotted in Figs. 3 and 4 along with the data in Fig. 4 recalculated for salt water.
We consider measurement of air-water exchange of $\mathrm{CO}_{2}$ and DMS at a height of $18 \mathrm{~m}$, wind speed $8 \mathrm{~m} \mathrm{~s}^{-1}, u_{*}=$ $0.28 \mathrm{~m} \mathrm{~s}^{-1}, f_{\mathrm{x}}=5 \mathrm{~Hz}$, and neutral stability $(z / L=0)$. From Fig. 3, we find $A P_{\mathrm{cov}}^{\prime}=161$ for covariance. From Fig. 4, we find $C P_{\mathrm{c}}=1.7 \times 10^{-4}$ for $\mathrm{CO}_{2}$ and $C P_{\mathrm{c}}=1.8 \times 10^{-3}$ for DMS (DMS is more soluble than $\mathrm{CO}_{2}$ ). For $\mathrm{CO}_{2}, R / \Delta C=$ 0.0027 and for DMS, $R / \Delta C=0.029$. This case for DMS is from Blomquist et al. (2010), where $\Delta C=2.0 \mathrm{ppbv}$, which yields $R=50 \mathrm{pptv}$. Their sensor has a white noise level of $4 \mathrm{pptv}^{2} / \mathrm{Hz}$, which, at $f_{\mathrm{x}}=5 \mathrm{~Hz}$, corresponds to a resolution of 6.3 pptv. Thus, sensor noise makes a negligible contribution to uncertainty in covariance DMS flux estimates with their device (see their Fig. 8). The situation is not as favorable for $\mathrm{CO}_{2}$. If we use a typical commercial sensor with resolution of $0.2-0.3 \mathrm{ppm}$, then we need $\Delta C>100 \mathrm{ppm}$ to obtain $<10 \%$ contribution of sensor noise to the flux uncertainty. Most of the open ocean has $\Delta C<20 \mathrm{ppm}$. Openocean $\mathrm{CO}_{2}$ flux measurements require almost an order of magnitude improvement in fast $\mathrm{CO}_{2}$ sensors to meet the requirement.

As an additional example, Perlinger et al. (2008) measured hexachlorobenzene (HCB) flux over Lake Superior as a function of downwind fetch from shore on 14 July 2006 using the modified Bowen ratio gradient method assuming a turbulent diffusion coefficient equal to that of sensible heat 


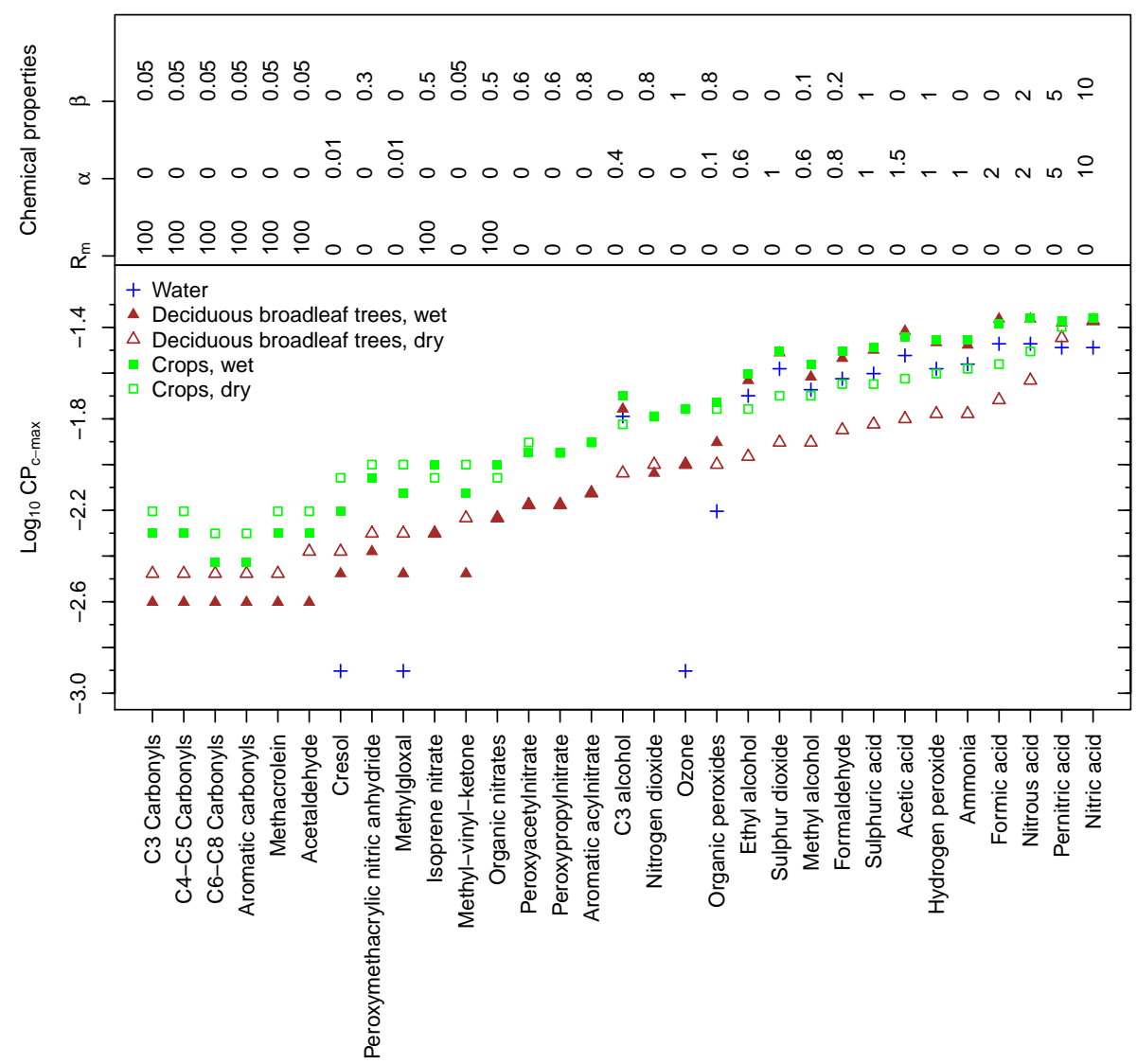

Fig. 5. Maximum values of the chemical parameter, $C P_{\mathrm{c}-\max }$, computed as in Eq. (35) for deposition of chemicals to land surface types and to water, using maximum deposition velocities given by Zhang et al. (2003). Parameters $\alpha$ and $\beta$ are scaling factors based on aqueous solubility and half-redox reactivity, respectively, and $R_{\mathrm{m}}$ is the mesophyll resistance in $\mathrm{s} \mathrm{m}^{-1}$ with values from Zhang et al. (2002).

with samplers at $z_{2}=10$ and $z_{1}=1 \mathrm{~m}$. At the 15-, 30-, and $60-\mathrm{km}$ fetch stations, $z / L=0.12,0.70,1.03,|\Delta C|=70,50$, $40 \mathrm{pg} \mathrm{m}^{-3}$, and from Fig. $3 A P_{\mathrm{g}}^{\prime}=5,9$, and 11 , respectively. Figure 4 gives $C P_{\mathrm{c}}$ of $4.3 \times 10^{-3}$ for $\mathrm{HCB}$. Application of Eq. (35) gives $R=0.1,0.2$, and $0.2 \mathrm{pg} \mathrm{m}^{-3}$ for the three stations, respectively. Rowe and Perlinger (2009) estimated an overall method precision of $9 \%$ from duplicate measurements, or ca. $5 \mathrm{pg} \mathrm{m}^{-3}$, indicating that greater method precision is required to reduce the contribution of sensor resolution to uncertainty in the flux measurement to $<10 \%$ using this method.

\subsection{Random noise/resolution contributions, flux uncertainty, and time averaging}

In their original treatment BD90 did not explicitly consider averaging time of the observations which may lead to some confusion in the interpretation of flux uncertainty versus the fraction of uncertainty contributed by noise and/or sensor resolution. Sample length must be addressed to explicitly account for uncertainty in covariance flux measurements. In Eqs. (11) and (16) it is clear that, while the resolution may contribute some fraction to the uncertainty, the total error can be reduced to an arbitrary limit by increasing the averaging time. Alternatively, an ensemble of data may be assembled and individual 1-h observations may be grouped (say, by wind speed) and averaged. The sampling uncertainty of a typical 1-h covariance flux estimate of a well-resolved scalar (such as water vapor) is on the order of $25 \%$ (Blomquist et al., 2010; Fairall et al., 2003). Thus, approximately six independent flux estimates could be averaged and the uncertainty of the average flux would be on the order of $10 \%$ (i.e., $25 \% / \sqrt{6}$ ). On the other hand, suppose a sensor with poor resolution is used and the total uncertainty for a 1-h observation is increased substantially. For example, consider the case for $\mathrm{CO}_{2}$ with a sensor resolution of $0.30 \mathrm{ppm}$ in conditions where $\Delta C=20 \mathrm{ppm}$, as discussed above. From Eq. (11) we estimate the flux uncertainty for a 1-h sample would be increased to $66 \%$. Now we would require almost 45 independent observations to be able to compute an average flux with uncertainty of $10 \%$.

An error analysis shows that the gradient method has some major differences compared to the covariance method. Consider the basic gradient flux equation from BD90

$\overline{w^{\prime} c^{\prime}}=-\frac{\kappa u_{*}}{G} \Delta C_{21}$ 
where $\Delta C_{21}$ is concentration difference between heights $z_{2}$ and $z_{1}$. An error expansion of Eq. (36) yields

$$
\left(\frac{\delta\left(\overline{w^{\prime} c^{\prime}}\right)_{T}}{\left(\overline{w^{\prime} c^{\prime}}\right)_{T}}\right)^{2}=\left(\frac{\delta u_{*}}{u_{*}}\right)^{2}+\left(\frac{\delta G}{G}\right)^{2}+\left(\frac{\delta\left(\Delta C_{21}\right)}{\Delta C_{21}}\right)^{2}
$$

Unlike the covariance flux, the uncertainty in the gradient flux also depends on the uncertainty of the determination of $u_{*}$ and the factor $G$ which may involve uncertainties in empirical stability functions and the estimate of $z / L$. (Note that for the modified Bowen ratio gradient approach mentioned in the example above, the first two terms on the right-hand side in Eq. (37) are replaced by $\left(\frac{\delta\left(\overline{w^{\prime} \theta^{\prime}}\right)_{T}}{\left(\overline{w^{\prime} \theta^{\prime}}\right)_{T}}\right)^{2}$ and $\left(\frac{\delta\left(\Delta \theta_{21}\right)}{\Delta \theta_{21}}\right)^{2}$, respectively, where $\theta$ represents potential temperature. In this case it is unnecessary to estimate $u_{*}$ and $G$ and their associated uncertainties.) The uncertainty in the concentration difference is

$$
\left(\delta\left(\Delta C_{21}\right)\right)^{2}=2\left(R^{2}+\sigma_{c_{\mathrm{a}}}^{2} \tau_{\mathrm{wc}} / T\right)
$$

This closely resembles Eq. (11) for covariance fluxes except now the resolution term characterizes the instrumental/analytical precision in the 1-h average concentrations (e.g., the $9 \%$ variability for $\mathrm{HCB}$ in the duplicate samples quoted by Perlinger et al., 2008), so it is not divided by $T$. If $T$ is sufficiently long the second term is negligible, and, if uncertainty in $u_{*}$ and $G$ are neglected, Eq. (37) reduces to BD90's original equation. For the modified Bowen ratio example above the second term in Eq. (38) will be less than $R^{2}$ when $T$ is greater than $1 \mathrm{~s}$, so the error in 1 -h samples is dominated by the precision of the chemical analysis. For example, the measurement precision $\left(5 \mathrm{pg} \mathrm{m}^{-3}\right)$ in this case is larger than the atmospheric variability $\left(\sigma_{\mathrm{c}}\right.$ about $\left.1 \mathrm{pg} \mathrm{m}^{-3}\right)$, so sampling variability does not contribute significantly to uncertainty. Even if these numbers $\left(R=0.2 \sigma_{\mathrm{c}}\right)$ were reversed atmospheric variability would be negligible for a 1-h average. Ensemble averaging can be used to reduce uncertainty for the gradient method in the same way as described for eddy covariance.

\section{Conclusions}

An updated and improved approach was described to estimate the required sensor resolution to limit to $10 \%$ the contribution of the sensor white noise to uncertainty in micrometeorological atmosphere-surface exchange flux measurements using eddy covariance, disjunct eddy covariance, gradient, and relaxed eddy accumulation methods. A change was made to the approach presented by Businger and Delany (1990), which results in a less stringent resolution requirement for eddy covariance than was estimated by their approach. The stability functions used to predict dimensionless standard deviation of a scalar caused by turbulent fluctuations were compared to water vapor measurements from recent field experiments. For $z / L<0$, there was good agreement between existing functions and the data, while for $z / L>0$ the various data sets do not agree. The functions proposed by Andreas et al. (1998) were selected as the best approximation to the data. The empirical functions, figures, and electronic supplemental material presented here can be used to consider the feasibility of flux measurement methods for planned field experiments.

\section{Appendix A}

\begin{tabular}{|c|c|}
\hline & empirical constant (-) \\
\hline$b$ & empirical coefficient $(-)$ \\
\hline$b_{\text {th }}$ & $\begin{array}{l}\text { three-reservoir REA calibration coefficient } \\
(-)\end{array}$ \\
\hline$c^{\prime}$ & turbulent fluctuation of scalar $C\left(\mathrm{~kg} \mathrm{~m}^{-3}\right)$ \\
\hline$c_{*}$ & $\begin{array}{l}\text { chemical flux scaling parameter }\left(-\overline{w^{\prime} c^{\prime}} / u_{*}\right) \\
\left(\mathrm{kg} \mathrm{m}^{-3}\right)\end{array}$ \\
\hline 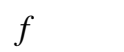 & frequency $\left(\mathrm{s}^{-1}\right)$ \\
\hline$f_{\mathrm{c}}(z / L)$ & $\begin{array}{l}\text { similarity function for dimensionless scalar } \\
\text { standard deviation (-) }\end{array}$ \\
\hline$f_{\mathrm{m}}$ & $\begin{array}{l}\text { frequency corresponding to the peak in the } \\
\text { vertical velocity or scalar variance spectral } \\
\text { density, or, alternatively, the } w-c \text { cospec- } \\
\text { trum }\left(\mathrm{s}^{-1}\right)\end{array}$ \\
\hline$f_{\mathrm{w}}(z / L)$ & $\begin{array}{l}\text { similarity function for vertical wind } \\
\text { velocity standard deviation }(-)\end{array}$ \\
\hline$f_{\tau}(z / L)$ & $\begin{array}{l}\text { similarity function for scalar integral time } \\
\text { scale (-) }\end{array}$ \\
\hline$f_{\mathrm{x}}$ & $\begin{array}{l}\text { maximum frequency of band-limited white } \\
\text { noise (Nyquist frequency) }\left(\mathrm{s}^{-1}\right)\end{array}$ \\
\hline$u_{*}$ & friction velocity $\left(\mathrm{m} \mathrm{s}^{-1}\right)$ \\
\hline$w^{\prime}$ & $\begin{array}{l}\text { turbulent variations of vertical velocity } \\
\left(\mathrm{m} \mathrm{s}^{-1}\right)\end{array}$ \\
\hline$\overline{w^{\prime} c^{\prime}}$ & $\begin{array}{l}\text { vertical turbulent flux of scalar } \\
C\left(\mathrm{~kg} \mathrm{~m}^{-2} \mathrm{~s}^{-1}\right)\end{array}$ \\
\hline$x$ & $\begin{array}{l}\text { subscript indicating flux } \\
\text { measurement method (either } \\
\text { cov }=\text { covariance, } g=\text { gradient, or } r=\text { relaxed } \\
\text { eddy accumulation) }(-)\end{array}$ \\
\hline$z$ & $\begin{array}{l}\text { distance upward from the surface }(\mathrm{m}) \text {. For } \\
\text { land-based measurements, } z-d \text { is used in } \\
\text { place of } z \text {, where } d \text { is the displacement height } \\
\text { of the canopy. }\end{array}$ \\
\hline$z_{2}, z_{1}$ & $\begin{array}{l}\text { upper and lower heights above the surface in } \\
\text { gradient flux measurement }(\mathrm{m})\end{array}$ \\
\hline$A, B$ & empirical coefficients (-) \\
\hline$A P_{\mathrm{x}}$ & $\begin{array}{l}\text { BD90 atmospheric parameter for flux } \\
\text { measurement method } x\left(\mathrm{~m}^{-1} \mathrm{~s}\right)\end{array}$ \\
\hline$A P_{\mathrm{x}}^{\prime}$ & redefined atmospheric parameter $(-)$ \\
\hline & concentration of scalar $C\left(\mathrm{~kg} \mathrm{~m}^{-3}\right)$ \\
\hline
\end{tabular}

\section{List of symbols with typical SI units}


M. D. Rowe et al.: Chemical sensor resolution requirements for near-surface measurements of turbulent fluxes

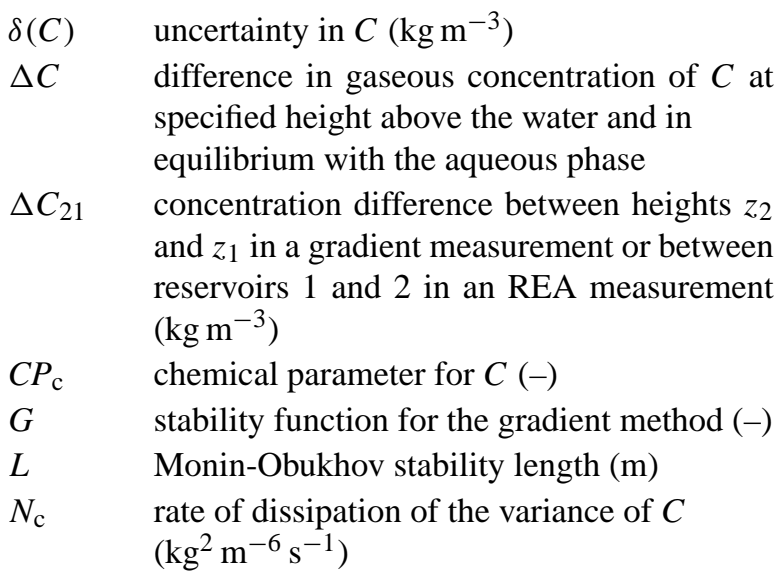

$R \quad$ sensor resolution required to conduct chemical flux measurement to an estimated $10 \%$ uncertainty $\left(\mathrm{kg} \mathrm{m}^{-3}\right)$

$R_{\mathrm{m}} \quad$ mesophyll resistance $\left(\mathrm{s} \mathrm{m}^{-1}\right)$

Sc $\quad$ Schmidt number (-)

$T \quad$ integral time period of a measurement (s)

$U_{\mathrm{r}} \quad$ mean wind speed relative to the sensor at the sensor height $\left(\mathrm{m} \mathrm{s}^{-1}\right)$

$\alpha_{\mathrm{c}} \quad$ dimensionless aqueous solubility (liquid over gas) of chemical $C$

$\alpha \quad$ an aqeous solubility scaling parameter in Fig. $5(-)$

$\beta \quad$ scaling parameter for half-redox reactivity $(-)$

$\theta \quad$ potential temperature $(\mathrm{K})$

$\kappa \quad$ von Kármán constant, assumed to have a value of $0.4(-)$

$k_{\mathrm{c}} \quad$ atmosphere-surface transfer velocity of scalar $C\left(\mathrm{~m} \mathrm{~s}^{-1}\right)$

$\sigma_{\mathrm{c}} \quad$ standard deviation of $C\left(\mathrm{~kg} \mathrm{~m}^{-3}\right)$

$\sigma_{\mathrm{c}_{\mathrm{a}}} \quad$ standard deviation of $C$ associated with turbulent fluctuations $\left(\mathrm{kg} \mathrm{m}^{-3}\right)$

$\sigma_{\mathrm{c}_{\mathrm{n}}} \quad$ standard deviation of $C$ associated with sensor white noise $\left(\mathrm{kg} \mathrm{m}^{-3}\right)$

$\sigma_{\mathrm{w}} \quad$ standard deviation of vertical wind velocity $\left(\mathrm{m} \mathrm{s}^{-1}\right)$

$\tau \quad$ integral (decorrelation) time scale

$\tau_{\mathrm{wc}} \quad$ covariance integral time scale (s)

$\tau_{\mathrm{c}_{\mathrm{n}}} \quad$ integral time scale associated with white noise in measurement of $C$ (s)

$\tau_{\mathrm{cD}} \quad$ turbulent mixing/dissipation time scale for variance of $C(\mathrm{~s})$

$\phi_{\mathrm{c}}(z / L) \quad$ similarity function for the dimensionless scalar mean gradient (-)

$\phi_{\mathrm{c}_{\mathrm{n}}} \quad$ variance spectral density of band-limited white noise in $C$ measurement $\left(\mathrm{kg}^{2} \mathrm{~m}^{-6} \mathrm{~s}\right)$

$\phi_{\sigma}(z / L) \quad$ similarity function for the dimensionless scalar standard deviation (-)
$\Delta \quad$ sample interval for disjunct or conventional eddy covariance $(s)$

$\psi(z / L) \quad$ similarity function for the dimensionless scalar vertical concentration profile (-)

\section{Supplementary material related to this \\ article is available online at: \\ http://www.atmos-chem-phys.net/11/5263/2011/ acp-11-5263-2011-supplement.zip.}

Acknowledgements. C. Fairall's contributions are supported by the NOAA Health of the Atmosphere Program and the NOAA Climate Observations Division.

Edited by: T. Karl

\section{References}

Andreas, E. L., Hill, R. J., Gosz, J. R., Moore, D. I., Otto, W. D., and Sarma, A. D.: Statistics of surface-layer turbulence over terrain with metre-scale heterogeneity, Bound.-Lay. Meteorol., 86, 379408, 1998.

Andreas, E. L., Jones, K. F., and Fairall, C. W.: The production velocity of sea spray droplets, J. Geophys. Res., 115, doi:10.1029/2010JC006458, 2010.

Aubinet, M., Grelle, A., Ibrom, A., Rannik, U., Moncrieff, J., Foken, T., Kowalski, A. S., Martin, P. H., Berbigier, P., Bernhofer, C., Clement, R., Elbers, J., Granier, A., Grunwald, T., Morgenstern, K., Pilegaard, K., Rebmann, C., Snijders, W., Valentini, R., and Vesala, T.: Estimates of the annual net carbon and water exchange of forests: The EUROFLUX methodology, Adv. Ecol. Res., 30, 113-175, doi10.1016/S0065-2504(08)60018-5, 1999.

Baldocchi, D. D.: Assessing ecosystem carbon balance: problems and prospects of the eddy covariance technique, Glob. Change Biol., 9, 479-492, 2003.

Baldocchi, D. D. and Harley, P. C.: Scaling carbon dioxide and water vapour exchange from leaf to canopy in a deciduous forest, II. Model testing and application, Plant Cell Environ., 18, 11571173, doi:10.1111/j.1365-3040.1995.tb00626.x, 1995.

Baldocchi, D. D., Fuentes, J. D., Bowling, D. R., Turnipseed, A. A., and Monson, R. K.: Scaling isoprene fluxes from leaves to canopies: Test cases over a boreal aspen and a mixed species temperate forest, J. Appl. Meteorol., 38, 885-898, 1999.

Blomquist, B. W., Fairall, C. W., Huebert, B. J., Kieber, D. J., and Westby, G. R.: DMS sea-air transfer velocity: Direct measurement by eddy covariance and parameterization based on the NOAA/COARE gas transfer model, Geophys. Res. Lett., 33, 14, 2006

Blomquist, B. W., Huebert, B. J., Fairall, C. W., and Faloona, I. C.: Determining the sea-air flux of dimethylsulfide by eddy correlation using mass spectrometry, Atmos. Meas. Tech., 3, 1-20, doi:10.5194/amt-3-1-2010, 2010.

Bowling, D. R., Delany, A. C., Turnipseed, A. A., and Baldocchi, D. D.: Modification of the relaxed eddy accumulation technique to maximize measured scalar mixing ratio differences in updrafts and downdrafts, J. Geophys. Res., 104, 9121-9133, 1999. 
Businger, J. A. and Delany, A. C.: Chemical sensor resolution required for measuring surface fluxes by three common micrometeorological techniques, J. Atmos. Chem., 10, 399-410, 1990.

Businger, J. A. and Oncley, S. P.: Flux measurement with conditional sampling, J. Atmos. Oceanogr. Technol., 7, 349-352, 1990.

Choi, T., Hong, J., Kim, J., Lee, H., Asanuma, J., Ishikawa, H., Tsukamoto, O., Zhiqui, G., Ma, Y., Ueno, K., Wang, J., Koike, T., and Yasunari, T.: Turbulent exchange of heat, water vapor, and momentum over a Tibetan prairie by eddy covariance and flux variance measurements, J. Geophys. Res., 109, D21106, doi:10.1029/2004JD004767, 2004.

DeSzoeke, S. P., Fairall, C. W., and Pezoa, S.: Ship observations of the tropical Pacific Ocean along the coast of South America, J. Climate, 22, 458-464, 2009.

Edson, J. and Fairall, C.: Similarity relationships in the marine atmospheric surface layer for terms in the TKE and scalar variance budgets, J. Atmos. Sci., 55, 2311-2338, 1998.

Fairall, C. W., Edson, J. B., and Miller, M. A.: Heat fluxes, whitecaps, and sea spray, in: Surface Waves and Fluxes, edited by: Geernaert, G. L. and Plant, W. J., Kluwer Academic Publishers, Netherlands, 173-208, 1990.

Fairall, C. W., Hare, J. E., Edson, J. B., and McGillis, W.: Parameterization and micrometeorological measurement of air-sea gas transfer, Bound.-Lay. Meteorol., 96, 63-105, 2000.

Fairall, C. W., Bradley, E. F., Hare, J. E., Grachev, A. A., and Edson, J. B.: Bulk parameterization of air-sea fluxes: updates and verification for the COARE Algorithm, J. Climate, 16, 571-591, 2003.

Fairall, C. W., Bariteau, L., Grachev, A. A., Hill, R. J., Wolfe, D. E., Brewer, W. A., Tucker, S. C., Hare, J. E., and Angevine, W. M.: Turbulent bulk transfer coefficients and ozone deposition velocity in the International Consortium for Atmospheric Research into Transport and Transformation, J. Geophys. Res., 111, D23S20, doi:10.1029/2006JD007597, 2006.

Grachev, A., Fairall, C., Persson, P., Andreas, E., Guest, P., and Jordan, R.: Turbulence decay in the stable Arctic boundary layer, Seventh Conference on Polar Meteorology and Oceanography and Joint Symposium on High-Latitude Climate Variations, Hyannis, MA, 2003.

Hilal, S. H., Carreira, L. A., and Karickhoff, S. W.: Prediction of the solubility, activity coefficient, gas/liquid and liquid/liquid distribution coefficients of organic compounds, SPARC OnLine Calculator http://archemcalc.com/sparc/ (last access: $7 \mathrm{Au}-$ gust 2010), QSAR Comb. Sci., 23, 709-720, 2004.

Hoppel, W. A., Frick, G. M., and Fitzgerald, J. W.: Surface source function for sea-salt aerosol and aerosol dry deposition to the ocean surface, J. Geophys. Res., 107, 1-17, doi:10.1029/2001JD002014, 2002.

Hoppel, W. A., Caffrey, P. F., and Frick, G. M.: Particle deposition on water: Surface source versus upwind source, J. Geophys. Res., 110, 1-15, doi:10.1029/2004JD005148, 2005.

Johnson, M. T.: A numerical scheme to calculate temperature and salinity dependent air-water transfer velocities for any gas, Ocean Sci., 6, 913-932, doi:10.5194/os-6-913-2010, 2010.

Kaimal, J. C. and Finnigan, J. J.: Atmospheric Boundary Layer Flows, Oxford University Press, New York, NY, 289 pp., 1994.

Karl, T. G., Spirig, C., Rinne, J., Stroud, C., Prevost, P., Greenberg, J., Fall, R., and Guenther, A.: Virtual disjunct eddy covari- ance measurements of organic compound fluxes from a subalpine forest using proton transfer reaction mass spectrometry, Atmos. Chem. Phys., 2, 279-291, doi:10.5194/acp-2-279-2002, 2002.

Lee, X., Massman, W. J., and Law, B. E.: Handbook of Micrometeorology, A Guide for Surface Flux Measurement and Analysis, Kluwer, Dordrecht, 250 pp., 2004.

Lenschow, D. and Kristensen, L.: Uncorrelated noise in turbulence measurements, J. Atmos. Oceanic Technol., 2, 68-81, 1985.

Lenschow, D. H., Mann, J., and Kristensen, L.: How long is long enough when measuring fluxes and other turbulence statistics?, J. Atmos. Ocean. Tech., 11, 661-673, 1994.

Leuning, R., Kelliher, F. M., de Pury, D. G. G., and Schulze, E.D.: Leaf nitrogen, photosynthesis, conductance, and transpiration: scaling from leaves to canopies, Plant Cell Environ., 18, 1183-1200, 1995.

Lindberg, S. E., Meyers, T. P., Taylor, G. E. J., Turner, R. R., and Schroeder, W. H.: Atmosphere-surface exchange of mercury in a forest: Results of modeling and gradient approaches, J. Geophys. Res., 97, 2519-2528, doi:10.1029/91JD02831, 1992.

Lindqvist, O.: Atmospheric mercury - a review, Tellus, 37B, 136159, 1985.

Mackay, D., Foster, K. L., Patwa, Z., and Webster, E.: Chemical partitioning to foliage: the contribution and legacy of davide calamari, Environ. Sci. Pollut. R., 13, 2-8, 2006.

McGillis, W. R., Edson, J. B., Zappa, C. J., Ware, J. D., McKenna, S. P., Terray, E. A., Hare, J. E., Fairall, C. W., Drennan, W., Donelan, M., DeGrandpre, M. D., Wanninkhof, R., and Feely, R. A.: Air-sea $\mathrm{CO}_{2}$ exchange in the equatorial Pacific, J. Geophys. Res., 109, C08S02, doi:10.1029/2003JC002256, 2004.

Panofsky, H. A. and Dutton, J. A.: Atmospheric Turbulence: Models and Methods for Engineering Applications, John Wiley and Sons, New York, NY, 397 pp., 1984.

Park, C., Schade, G. W., and Boedeker, I.: Flux measurements of volatile organic compounds by the relaxed eddy accumulation method combined with a GC-FID system in urban Houston, Texas, Atmos. Environ., 44, 2605-2614, 2010.

Perlinger, J. A., Rowe, M. D., and Tobias, D. E.: Atmospheric transport and air-water exchange of hexachlorobenzene in Lake Superior, Organohalogen Compounds, 70, 598-601, 2008.

Perlinger, J. A., Tobias, D. E., Morrow, P. S., and Doskey, P. V.: Evaluation of novel techniques for measurement of air-water exchange of persistent bioaccumulative toxicants in Lake Superior, Environ. Sci. Technol., 39, 8411-8419, 2005.

Pryor, S. C., Gallagher, M., Sievering, H., Larsen, S. E., Barthelmie, R. J., Birsan, F., Nemitz, E., Rinne, J., Kulmala, M., Gronholm, T., Taipale, R., and Vesala, T.: A review of measurement and modelling results of particle atmosphere-surface exchange, Tellus, 60B, 42-75, 2008.

Rinne, J., Douffet, T., Prigent, Y., and Durand, P.: Field comparison of disjunct and conventional eddy covariance techniques for trace gas flux measurements, Environ. Pollut., 152, 630-635, 2008.

Rowe, M. D. and Perlinger, J. A.: Gas-phase cleanup method for analysis of trace atmospheric semivolatile organic compounds by thermal desorption from diffusion denuders, J. Chromatogr. A, 1216, 5940-5948, doi:10.1016/j.chroma.2009.06.034, 2009.

Sander, R.: Compilation of Henry's Law Constants for Inorganic and Organic Species of Potential Importance in Environmental Chemistry (Version 3), available at: www.henrys-law.org (last access:20 June 2010), 1999. 
Sanemasa, I.: The solubility of elemental mercury vapor in water, B. Chem. Soc. Jpn., 48, 1795-1798, 1975.

Turnipseed, A. A., Pressley, S. N., Karl, T., Lamb, B., Nemitz, E., Allwine, E., Cooper, W. A., Shertz, S., and Guenther, A. B.: The use of disjunct eddy sampling methods for the determination of ecosystem level fluxes of trace gases, Atmos. Chem. Phys., 9, 981-994, doi:10.5194/acp-9-981-2009, 2009.

Walker, J. T., Robarge, W. P., Wu, Y., and Meyers, T. P.: Measurement of bi-directional ammonia fluxes over soybean using the modified Bowen-ratio technique, Agr. Forest Meteorol., 138, 54-68, 2006.

Wesely, M. L.: Parameterization of surface resistances to gaseous dry deposition in regional-scale numerical models, Atmos. Environ., 23, 1293-1304, 1989.
Wolfe, G. M. and Thornton, J. A.: The Chemistry of AtmosphereForest Exchange (CAFE) Model - Part 1: Model description and characterization, Atmos. Chem. Phys., 11, 77-101, doi:10.5194/acp-11-77-2011, 2011.

Zhang, L., Brook, J. R., and Vet, R.: A revised parameterization for gaseous dry deposition in air-quality models, Atmos. Chem. Phys., 3, 2067-2082, doi:10.5194/acp-3-2067-2003, 2003.

Zhang, L., Moran, M. D., Makar, P. A., Brook, J. R., and Gong, S.: Modelling gaseous dry deposition in AURAMS: a unified regional air-quality modelling system, Atmos. Environ., 36, 537560, 2002. 